\title{
The legal status of Uncertainty
}

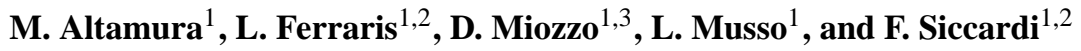 \\ ${ }^{1}$ CIMA Research Foundation, Via A. Magliotto 2, 17100, Savona, Italy \\ ${ }^{2}$ DIST, Department of Communication, Computer and System Sciences, University of Genova, Via Opera Pia 13, \\ 16145 Genova, Italy \\ ${ }^{3}$ DISMEC, Department of Modern and Contemporary History, University of Genova, Via Balbi, 6, 16126, Genova, Italy
}

Received: 5 July 2010 - Revised: 11 November 2010 - Accepted: 17 December 2010 - Published: 14 March 2011

\begin{abstract}
An exponential improvement of numerical weather prediction (NWP) models was observed during the last decade (Lynch, 2008). Civil Protection (CP) systems exploited Meteo services in order to redeploy their actions towards the prediction and prevention of events rather than towards an exclusively response-oriented mechanism ${ }^{1}$.

Nevertheless, experience tells us that NWP models, even if assisted by real time observations, are far from being deterministic. Complications frequently emerge in medium to long range forecasting, which are subject to sudden modifications. On the other hand, short term forecasts, if seen through the lens of criminal trials ${ }^{2}$, are to the same extent, scarcely reliable (Molini et al., 2009).

One particular episode related with wrong forecasts, in the Italian panorama, has deeply frightened CP operators as the NWP model in force missed a meteorological adversity which, in fact, caused death and dealt severe damage in the province of Vibo Valentia (2006). This event turned into a very discussed trial, lasting over three years, and intended against whom assumed the legal position of guardianship within the CP. A first set of data is now available showing that in concomitance with the trial of Vibo Valentia the number of alerts issued raised almost three folds. We sustain the hypothesis that the beginning of the process of overcriminalization (Husak, 2008) of CPs is currently increasing the number of false alerts with the consequent effect of weakening alert perception and response by the citizenship (Brezntiz, 1984).
\end{abstract}

Correspondence to: D. Miozzo

(davide.miozzo@cimafoundation.org)
The common misunderstanding of such an issue, i.e. the inherent uncertainty in weather predictions, mainly by prosecutors and judges, and generally by whom deals with law and justice, is creating the basis for a defensive behaviour $^{3}$ within CPs. This paper intends, thus, to analyse the social and legal relevance of uncertainty in the process of issuing meteo-hydrological alerts by CPs.

\footnotetext{
${ }^{1}$ The Italian Civil Protection is working in this direction since 1992 (L. 225/92). An example of this effort is clearly given by the Prime Minister Decree (DPCM 20/12/2001 "Linee guida relative ai piani regionali per la programmazione delle attivita' di previsione, prevenzione e lotta attiva contro gli incendi boschivi - Guidelines for regional plans for the planning of prediction, prevention and forest fires fighting activities") that, already in 2001, emphasized "the most appropriate approach to pursue the preservation of forests is to promote and encourage prediction and prevention activities rather than giving priority to the emergencyphase focused on fire-fighting".

${ }^{2}$ Supreme Court of the United States, In re Winship (No. 778), No. 778 argued: 20 January 1970, decided: 31 March 1970: Proof beyond a reasonable doubt, which is required by the Due Process Clause in criminal trials, is among the "essentials of due process and fair treatment"

${ }^{3}$ In Kessler and McClellan (1996): "Defensive medicine is a potentially serious social problem: if fear of liability drives health care providers to administer treatments that do not have worthwhile medical benefits, then the current liability system may generate inefficiencies much larger than the costs of compensating malpractice claimants".
} 


\section{Introduction}

The role of CPs, and the role of their directors, is jeopardized when the inherent uncertainty of natural and man made hazards affects their decisions (UNISDR, 2009a). Numerous judgments are proven wrong by post-event analysis which, however, differ from real time decisions in the substantial facilitations of already knowing the ground effects of the given hazard and in having all the necessary time for evaluating the congruence of the decision chain.

Knowing the uncertain response that any hydrometeorological event has on a particular ground, CP directors, or whom has the legal responsibility to fulfil such an obligation, the guardian (De Franchis, 1996), needs to make decisions in a very short time interval. These decisions can be demonstrated, ex-post, as wrong. Decision makers involved in the process are condemned to face trial due to the institution of mandatory prosecution which enters into force as soon as a previously codified crime is committed. In Italy, such an obligation is enucleated in the Constitution; art. 112: "Il pubblico ministero ha l'obbligo di esercitare l'azione penale" (the prosecutor has the obligation to purse the criminal action). Part of the overcriminalization problem is inherent to such an inflexible imposition by criminal law. The natural answer to the risk of being trialled is the elimination of discretionality by $\mathrm{CP}$ operators whom are issueing a larger number of alerts in order not to face imputation. However, the vulnus of this perception is that guarantors face imputation even if the NWP models at their disposal are not able to provide information on the incoming risk scenarios. NWP models in fact are subject to uncertainty in the ability of positioning the precipitation both in space and time. CP directors and guarantors increased significantly the number of alerts issued in the past years in the case of forecasted events. CIMA Foundation has studied such a trend in Italy since 2006 (in 2005 the institution of alerts was implemented). Coupling the number of alerts with the number of given events per year, it was observed that in 2009, $65 \%$ of the 131 alerts issued by the Italian CP, where false alerts; such a percentage rose from an initial (2006) $37 \%$. The increase shows that the effects of the self-protective attitude adopted by the system are immediate. Precaution, as observed has risen amongst $\mathrm{CP}$ operators in the recent years consequently lowering the political threshold for issuing alerts. From this behaviour stems, inevitably, the so called "cry wolf syndrome", morale of Aesop's most famous tale "the boy whom cried wolf", which, transposed into modern times, risks to reduce the due vigilance of citizens and the institutions that are meant to protect them.

This kind of lawful dispositions would contribute to the definition of tort and ensure a correct application of the law only if the models used for the definition of alert and preevent procedures were to be considered deterministic. The principle incerta pro nullis habentur (things uncertain are held for nothing), fundament of criminal procedures, seems, in this specific case, to be unapplied. It is beyond doubt that the affirmation of the right to be protected by meteorological adversities, today diffused and recognized throughout our countries, should focus on the concept that natural hazards cannot be prevented but catastrophic consequences can be avoided or minimized by any mean. To this end, it is important, in the name of the diffusion of a widespread safety within our societies, to mediate between:

- The protection of rights and interests to the victims of natural and man made catastrophes.

- The progress of Science and the development of new Technologies.

- The development of an efficient CP system.

- The protection of $\mathrm{CP}$ operators from unjust incriminations.

- The affirmation of Criminal Law which is not, however, to compromise the fundamental values of freedom.

In this paper we will give a multidisciplinary point of view of the importance of communicating the real degree of accuracy of NWP models used by National CP. The aim is to propose a different approach in the definition of guilt within the CP system and relieve the already critically high legal pressure in order to impede the possible collapse of the organization.

\section{A multidisciplinary approach to the problem of overcriminalization}

As already experienced by medical sciences in the organization of health structures ${ }^{4}$, the phenomenon of overcriminalization, correlated with the defensive behaviour of individuals in performing their professional tasks, represent a serious setback for the functionality, overall costs and access to services, with unsustainable social and economic consequences. When someone deals with natural events and their possible catastrophic consequences, foremost in the scientific community, he might not be used to reason with a legal/jurisprudential approach. The same reasoning

\footnotetext{
${ }^{4}$ Herewith are reported examples of Defensive Medicine and its cost on society: "For more than two decades, advocates of malpractice system reform have claimed that the most damaging and costly result of the US medical malpractice system is the practice of defensive medicine, in which physicians order tests and procedures primarily because of fear of malpractice liability" (Klingman et al., 1996). Defensive medicine is highly prevalent among physicians in Pennsylvania who pay the most for liability insurance, with potentially serious implications for cost, access, and both technical and interpersonal quality of care (Studdert et al., 2005)
} 
works vice versa, judges often do not have the competence to examine omissive behaviours in this topic and must relay on external experts. Modern society in developed countries, with particular reference to the administration of justice, is non the less increasingly concerned with such themes. There is a profound urge to train a category of experts capable to approach the problem in a multidisciplinary way.

Experience tells us that in the case of a disastrous event that has caused deaths and/or property damage, the Operator of CP may become subject of criminal charges if he fails in putting in place all the necessary means in order to prevent its effects. In all the legal systems of our countries, the cornerstone of omissive crimes is the legal obligation to prevent the harmful consequences of an event. Whom holds the legal obligation to do so, is invested by the so called position of tutelage (from latin tutela, protection). In Common law countries the institute of tutelage does not exist as intended by Civil lawyers. The closest analogous to the guardian (he whom holds the tutelage) is the guardian or the protector (Lawson et al., 1967).

Clearly, the obligation to avoid natural calamities cannot exist, as the correlated power is unachievable. However, the obligation to avoid harmful consequences of hydrometeorological events surely exists and is codified by CP laws. The Italian CP law (L. 225/92) identifies prevention activities (art. 2) addressing them to the reduction of damages produced by the impact of natural events (art. 3). Moreover specific institutional positions are invested with specific obligations (artt. 14, 15). The omission of the mentioned provision implies, in the event of damage to goods or people, the accomplishment of an omissive crime. Society, moreover, does not tolerate human life and propriety losses, especially coming from natural hazards that could have been predicted. The invisible, but solid, connection between societal perceptions and jurisprudential studies brings citizens to pretend punishment for whom failed to protect human life and property in case of a natural event and to be compensated for their losses.

The identification of guilt within CP prevention activities deals with a complexity of problems that attain to a multiplicity of disciplines. The term prevention, in this case, is used in its general acception which comprises real time actions, the forecast of the natural hazard and the actions taken in differed time intended to mitigate the effects of the natural hazard. Our societies cope with this complexity by putting into service CP organizations and by controlling their efficiency by the means of criminal justice. This solution appears nonetheless as unconvincing. Individuals must be protected by omissive actions but, to the same extent, $\mathrm{CP}$ operators must be given the chance to work without fearing unjust indictments. The existing partition between the administration of justice, science and CP institutions should be filled by a transversal effort intended to grant a coherent defence of human rights as well as the sustainability of institutions that demonstrated, over the years, to be valuable ${ }^{5}$.

\section{Liability in Civil Protection - the concept of "guardianship"}

As previously discussed, liability of $\mathrm{CP}$ operators is usually an omissive liability. The key notion of this concept is the lawful obligation to prevent an incident. The chain of causation will not be based on facere (latin for to do) but focuses on the omission of a specific action. Such a principle is enshrined in Art. 40 of the Italian criminal code:

"Non impedire un evento, che si ha l'obbligo giuridico di impedire, equivale a cagionarlo" (not to impede an event, towards which there is a lawful obligation to prevent its happening, is equivalent to cause it) or, in other words, if he who had the power to impede an event does not take the adequate actions to do so and, thus, causes death, injury or propriety loss can be held liable to the same extent as if he had caused the event.

In the context of Civil Protection, the authorities responsible for the protection of people and their goods, are physical persons endorsed with the obligation of preventing the occurrence of human life and property loss. For what concerns Italy, for example, they are the Mayor, the Prefect, the President of the Region, the head of the Centro Funzionale and the director of the CP. Such a lawful obligation, and the consequent legal position of the authorities, must always counterpart with the criminal justice system. The guardian can be held liable exclusively if: the provision of tutelage existed before the event, such a provision had been previously codified (by rule or by law) at the time of the event and if he (the guardian) is acknowledgeable.

Reassuming, the positions of tutelage has two distinctive profiles:

1. Tutelage of Protection (preserving the protected from the dangers that threaten him).

2. Tutelage of Control (neutralizing the sources of danger that threaten the protected assets).

From this legal bond arises the criminal nature of liability and, thus, the legal system rigorously identifies it .The obligation to prevent an event, and the resulting position of guarantee, must fulfil criminal codes and laws and in

\footnotetext{
${ }^{5}$ OECD (2010): "A multi-risk approach to large scale disaster management has been established in Italy covering the whole range of severe risks and possible crises situations. It fully integrates scientific research and technological expertise in a structured system for maintaining an excellent early warning capacity, covering the emergency management cycle's phases, i.e. forecasting, conducting surveillance and monitoring, risk prevention, emergency response and overcoming or recovery [... ]"
} 
particular must be compliant with the principle of nulla poena sine lege (lit.: no crime without law). As defined by art. 7 of the European Convention on Human Rights, Rome, 1950: "No one shall be held guilty of any criminal offence on account of any act or omission which did not constitute a criminal offence under national or international law at the time when it was committed."

The tutelage, furthermore, must be logically directed to the protection of goods and people towards which the guardian refers. It is obvious that such a protection duty must be based on the existence of legal and financial means that grant the effective powers endorsed by the tutelage in order to forestall the happening of an event.

However, when this legal institution comprises actions and decisions that must be taken by scientific means, it is worth keeping in mind the presence of an element of disturbance of great importance which is uncertainty.

Uncertainty itself is fundament of judge's Blackmun ruling in Daubert Vs Merrell Dow (Stella, 2003) for whom "there are no certainties in science" 6 and "in the case of a particular scientific technique, the court ordinarily should consider the known or potential rate of error" 7 .

It is helpful to remind that criminal law is the utter and foremost mean of reducing the freedom granted by our democratic orders. The significance of the possible punishment thus requires a stronger probative evidence than Civil procedures. Criminal proceedings, opposed to Civil trials, need a higher level of confidence as the former entail evidence beyond any reasonable doubt, while the later only require a preponderant probability. The twofold effects of such a constrain, on the one hand, penalize plaintiffs for they will scarcely succeed in being compensated by a criminal proceeding, especially if the omission is based on a wrong utilization of NWP models that are intrinsically uncertain. On the second hand it introduces a dangerous automatism inducing the operators of $\mathrm{CP}$ to issue an excessive amount of alerts as hard proof of due diligence. By so doing the number of false alerts will forcedly increase in the years to come. One of the most important collateral effects of endorsing this protective attitude is the concretization of the so called cry wolf (Brezntiz, 1984) syndrome with long term detrimental effects on the perception of inefficiency of the $\mathrm{CP}$ by civilians.

\section{Legal obligations in risk management activities}

Risk management activities focus on the definition of a prevention and preparedness plan. Disaster risk reduction strategies are profitably being implemented throughout Europe thanks to an intense application of these activities. Other than national CPs, supranational organizations and

\footnotetext{
${ }^{6}$ Supreme Court of United States, 1993

${ }^{7}$ Ibid.
}

Table 1. Alerts vs. events in Italy from 2006 to 2009.

\begin{tabular}{cccc}
\hline Year & $\begin{array}{c}\text { Number } \\
\text { of Alerts }\end{array}$ & $\begin{array}{c}\text { Number } \\
\text { of Events } \\
>50 \mathrm{~mm} \mathrm{~h}^{-1}\end{array}$ & $\begin{array}{c}\text { \% False } \\
\text { Alerts }\end{array}$ \\
\hline 2006 & 54 & 34 & 0.37 \\
2007 & 49 & 9 & 0.82 \\
2008 & 80 & 24 & 0.70 \\
2009 & 131 & 46 & 0.65 \\
\hline
\end{tabular}

institutions, such as the European $\mathrm{CP}^{8}$; and the United Nation ISDR program ${ }^{9}$, focus on the need to strengthen prevention and preparedness strategies.

The enhancement of the functionality of a peoplecantered system, an effectiveness of CP organizations, which have strongly implemented early warning strategies, must comprise four key elements:

"Knowledge of the risk; monitoring, analysis and forecasting of the hazards; communication or dissemination of alerts and warnings; and local capabilities to respond to the warnings received" (UNISDR, 2009b).

Subject of paramount importance, is the safeguard of persons and their lives which is the highest right protected by our justice systems. Life, above all, is being better protected also thanks to the amelioration of Civil Protection mechanisms throughout our countries.

Nevertheless, this system could be endanger in the event of an erratic over communication of alerts due to an excessive solicitation of the Civil Protection by Criminal Justice for pre-event and real time activities. The attempt of identifying a causal connection between the number of alerts issued and the defensive behaviour assumed by $\mathrm{CP}$ operators lead to the analysis of the total number of alerts issued Italian CP over a four years period. The institution of meteorological alerts, in Italy, began with the promulgation of DPCM 27 February 2004 which recognized to the 21 Italian regions, since 1 September 2005, full autonomy on the emission, and

\footnotetext{
${ }^{8}$ Euratom, 2007/162/EC, Art. 3:

d) "preparedness" means a state of readiness and capability of human and material means enabling them to ensure an effective rapid response to an emergency, obtained as a result of action taken in advance;

e) "prevention" means any action that supports Member States in preventing risks or reducing harm to people, the environment or property resulting from emergencies.

${ }^{9}$ UNISDR Mission, as from the official home page of the programme: "the ISDR aims at building disaster resilient communities by promoting increased awareness of the importance of disaster reduction as an integral component of sustainable development, with the goal of reducing human, social, economic and environmental losses due to natural hazards and related technological and environmental disasters", http://www.unisdr. org/.
} 
Hydrometeorological Events Vs Alerts issued by CP

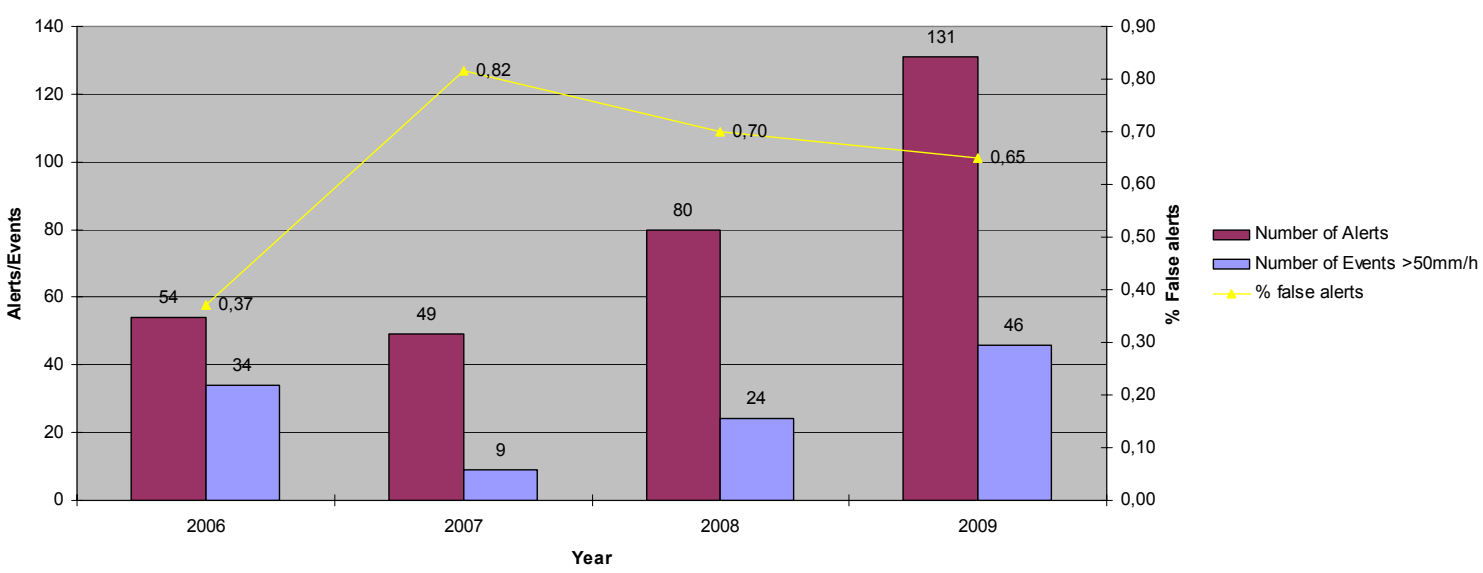

Fig. 1. Hydrometeorological events vs. Alerts issued by CP in Italy from 2006 to 2009.

cessation, of meteorological alerts. Valuable data is thus available only from 2006. Keeping in mind that a statistical series of four years is not robust, it is however interesting to observe (Table 1 and Fig. 1) how, in such a short time, the numbers of false alerts and, alerts themselves, have constantly increased since their adoption. The displayed data was obtained coupling the alerts issued by the Italian CP and the analysis of meteorological events registered by the pluviometric network.

A first analysis of the observed trend shows both the increase of alerts issued (80\% for the period 2006-2009) and highlights an anomalous behaviour in 2006; year with the least events registered of the whole series but with the highest percentage of false alerts (82\% opposed to an average of $57 \%$ during the other 3 years). For this type of study we have considered as relevant only events for which at least one sensor on the Italian territory has registered a $50 \mathrm{~mm} \mathrm{~h}^{-1}$ rainfall. In 2007 this type of event was observed only 9 times opposed to 34 (2006), 24 (2008) and 46 (2009).

The guidelines that establish operative procedures are based on the individuation of the so called precursors of an event. With reference to hydrometeorological risk, pluviometric and hydrometric thresholds are paired with different levels of risk that mostly depend on the vulnerability and morphology of the given territory. The thresholds have a technical component which refers to rainfalls with return of 2, 5 and 20 years (ordinary, moderate and elevated alert respectively) circumstantiated within the alert areas defined in the Italian territory, which are portions of territory significantly homogeneous for the expected manifestation of typology and severity of intense hydrometeorological events and their relative effects (DPCM 27 February 2004). And a "political" component that we could call "discretionality of the CP operators". In fact, the eventual overcoming of the aforesaid thresholds do not imply the automatic release of an alert which are instead dependant to the analysis of experts whom, case by case, decide when an event can correspond to a real risk.

The effect of the abovementioned defensive behaviour has resulted in an increase of the number of issued alerts augmenting, de facto, the percentage of false positives. This means that lesser place is being given to discretionality of $\mathrm{CP}$ operators and, instead, the automatism threshold-alert is becoming a procedural constant.

The second observation that we advanced is that the year with the highest number of false alerts was 2007 which, however, was also the year with the lesser number of meteorological events exceeding $50 \mathrm{~mm} \mathrm{~h}^{-1}$. In our opinion, the cause of this behaviour can be found in the reaction to a specific trial against operators of $\mathrm{CP}$ and local authorities after the episode of a severe meteorological event that struck southern Italy in 2006. The unexpected increase of false alerts must not be ascribed to careless inaccuracy of the $\mathrm{CP}$ but, rather, to the initial effects of the defensive behaviour. We will come back and detail better the case of Vibo Valentia later but, for now, it is important to anticipate that the defendants were found not guilty as the NWP model used to compile the daily risk bulletin didn't forecast correctly the incoming event.

CP operators and decision makers are pushed to issue alerts every time that a threshold is reached. Assuming that the risk of being convicted is valid even in the case of missed functions of its fundamental instruments, defensive conducts are surely expected to be reiterated in time.

The problems correlated with the defensive behaviour of $\mathrm{CP}$ are both of jurisprudential and social order. On the one hand criminal law cannot be the mean of controlling the efficiency $\mathrm{CP}$ systems that endeavour weather forecast and risk assessment. This process risks to give birth to hypothesis of objective criminal liability (liability without 
fault, associated to a social role and to an hypothetical and abstract causality) rather than personal/individual liability (associated to a specific omission and to a concrete causality). This kind of criminal law compromises the values of freedom of innocent people, that are at the basis of criminal proceedings of democratic systems, evading the evoked principle of "incerta pro nullis habentur". There are however lawful constrains that enforce self-generating loops: i.e. art. 112 Cost. of the Italian Constitution, obliges prosecutors, after the acquisition of a notitia criminis, to initiate preliminary investigations conducted to verify the need for a full trial. These investigations, even if they bring to nothing, are however long lasting and costly.

On the other hand, the due importance must be given to a correct communication of the risk. An excessive issuing of alerts will generate high cost for the implementation of all the procedures necessary to cope with the eventuality of natural hazards. As in medicine the structure risks to see a swift increase of its costs with a direct fall on the general taxation. The communication of risk itself can be put in crisis by the cry wolf syndrome or, worse, by an indiscriminate and generalized utilization of the instrument of alerting the competent authorities. Such a problem is one of the main concerns of smaller towns which, most of the times, don't have the financial and technical means to instruct a functional emergency plan of $\mathrm{CP}$ thus leaving the population to itself. The utter outpost of $\mathrm{CP}$ is in fact bonded to the efficiency of the "last mile" implying a flawless and synergic communication between the core and the periphery of CP systems.

\section{Defensive behaviour}

As explained, medical sciences have been experiencing the effects of defensive medicine (Studdert et al., 2005) long enough to draw some conclusions that appear useful to understand the added costs of such a defensive behaviour. The legal exposition of physicians mostly discharges on the general taxation and on disservices of the medical infrastructures themselves.

The adoption of evasive procedures by physicians demonstrates that the process of formalization into practical guidelines of initiatives, specifically intended to avoid frequent charges and lawsuits, is a current and felt problem.

$\mathrm{CP}$ environments are eliminating discretionality in the process of determining the existence of risk. The automatism: critical level - threshold - alert is replacing it. To the same extent physicians are adopting exhaustive protocols in the attempt of reducing the level of exposure to criminal prosecutions. But, as defensive medicine should be criticized for its inefficiency and costs also the thresholdalert system appears as not convincing. The affirmation of such a trend could bring the alert threshold to an excessive precautionary level thus frustrating the assignment of science in finding more accurate answers to current problems. Moreover, liability of CP operators cannot be excluded even if they have thoroughly followed the foreseen procedures.

An interesting debate on the danger of doctrinal feedback on medical care states that "overcautious practice feeds back into doctrine, making negligence law more demanding and requiring physicians to use medically unnecessary and wasteful technique" (Gibson, 2008). The example proposed by Gibson, supporter of this theses, sees a physician that, in order to exercise reasonable care, overcomplies by requiring more detailed analysis. As isolated incident, such overcompliance cannot be considered troubling; but if a sufficient number of physicians were to follow the same behaviour "it will eventually cease to constitute more than reasonable care, because reasonable care draws its definition from the typical conduct of those it regulates" (Gibson, 2008).

The concept of reasonable care can be extrapolated from an English famous case, "Bolam v Friern Hospital Management Committee", considered a milestone in tort law. The judgment, expressed by Judge McNair, gives us a significant opinion on reasonable care:

"I myself would prefer to put it this way, that he is not guilty of negligence if he has acted in accordance with a practice accepted as proper by a responsible body of medical men skilled in that particular art. I do not think there is much difference in sense. It is just a different way of expressing the same thought. Putting it the other way round, a man is not negligent, if he is acting in accordance with such a practice, merely because there is a body of opinion who would take a contrary view. At the same time, that does not mean that a medical man can obstinately and pig-headedly carry on with some old technique if it has been proved to be contrary to what is really substantially the whole of informed medical opinion. Otherwise you might get men today saying: 'I do not believe in anaesthetics. I do not believe in antiseptics. I am going to continue to do my surgery in the way it was done in the eighteenth century.' That clearly would be wrong" (Bolam v The Friern, 1957).

The sharpness of this line of thought has to be considered in the light of the doctrinal feedback above mentioned. If the "proper" practice is constantly pushed towards an overcompliant horizon then it becomes costly and unreachable for most; in the case of CP the poorest and smallest municipalities would pay the burden of overcompliance falling inevitably in the pit of incompetence. The implication of this vicious circle has had a direct influence on the costs and accessibility of the service. Health care professionals, in fact, defend themselves in two ways: on the one hand buying medical malpractice insurances (which results in an increase of the overall cost) and, on the second hand by avoiding risky practices (reduced accessibility to the service). An example of such a phenomenon is the extremely high percentage of uninsured $(15.3 \%)$ and underinsured $(35 \%)$ population in the US (U.S. Census Bureau, 2008). 
Judge McNair also explores what might be considered risk management activities. If people did not trust the new techniques of weather forecast, Civil Protections interventions would still be focusing on responsiveness rather than prevention and forecasting.

Pushing foreword this comparison, the concept of doctrinal feedback can be applied to Civil Protection operations in the field of meteorological forecast and risk assessment. The institution of alerting the population after a careful analysis of NWP models risks to follow the same overcautious loop. When alert issuing will become a normality, other and more expensive actions will be required in order to be compliant in front of the law. As the budget will presumably remain constant in the following years, this path will frustrate science in favour of the raising administrative costs.

The current system, mined with dysfunctions, pushes CP operators to be over-conservative and gives no incentives to improve eventual faulty judgments. Contrariwise, deterrence or, rather, overdeterrence, the phenomenon according to which a penalty, greater than the level that internalizes the social loss, is inflicted (Olson, 1988), is a common agenda in this specific sector of tort law.

We should ask ourselves if we can trial a guarantor of $\mathrm{CP}$ for being compliant with a NWP model that, by definition, is embodied with uncertainty. Can we judge someone's actions if he has followed what the scientific community at large, despite the accepted margin of error, defines as state of the art technology?

The answer to these questions is unfortunately positive and in the next chapters we will give examples of the legal effects of this faultiness.

\section{The case of Vibo Valentia - a practical example of the legal consequences of uncertainty in NWP models}

Reassuming, on the one hand judges are often obliged, by law, to pursue criminal proceedings as soon as a notitia criminis (a notice conveyed to a prosecutor that a crime is alleged to have occurred) is acquired by the public prosecutor, while, on the other hand, $\mathrm{CP}$ organizations relay on NWP models, by far not deterministic, where on the contrary, uncertainty plays an important role. The risks that the entire system faces in ignoring this dangerous self generating loop are of primary importance. This section will give an example on the costs of this malfunction for both the society and for CP operators.

In the recent summer of 2006, a violent meteorological event hit the Italian town of Vibo Valentia. In less than four hours, more than $200 \mathrm{~mm}$ rained over a three hours period on a $15 \mathrm{~km}^{2}$ area causing the deceases of four and extensive damage to infrastructures.

The trial that stemmed from this event, saw, amongst the ten defendants, a general director of Civil Protection, guarantor for the "forecast, evaluation, prevention and mitigation of anthropic risks" division. The anomaly of this legal episode cannot be found in the event per se as it is the mere and lawful application of the regulations in force in the Italian legal order; the anomaly is rather in the imputations addressed by the prosecutor whom asked to pursue an investigation to assess the defendants' liability for:

"having caused landslides and floods, as officer in duty for the forecast and prevention of natural risks office within the Department of Civil Protection, as negligently failing to comply with the obligations related to that position because, despite the existence of a meteorological phenomenon whose severity was predictable and expected, failed to issue an alert of adverse weather conditions" (Vibo Valentia Law Court, Office of the Judge for Preliminary Investigations, Reg. Sent. 76/09, 6 September 2009).

After a preliminary inquiry, the charges were dismissed as experts demonstrated the complete exclusion of the causal relation between the events and the defendants. Ex-post analysis made it clear that the meteorological event was not correctly forecasted by numerical models and no possible alternative means (radar image or satellite data), also due to the delay of data transfer, could have corrected the missed forecast.

Researchers at CIMA Foundation studied the event showing that its forecasting path can be ascribed amongst the list of missed alerts. The reliability of NWP, continues the paper, reaches a $90 \%$ rate of correct forecasts for ordinary events whilst lowers to $35 \%$ for extreme events (Molini et al., 2009).

On these basis, it is important to interrogate ourselves to what extent can the administration of justice accept the risk of condemning an operator of CP that must relay on such faulty instruments.

\section{Prosecution of crimes}

An important initiative, in the sense of improving such a system, could relate to the prosecution of crimes itself in our countries.

A judge asked to formulate an indictment (in reference to a natural disaster) should always ask himself the following questions:

- What happened?

- Why did it happen?

- Was the event predictable?

- Was the event avoidable?

In this case it is important to stress the fact that in jurisprudential terms we refer to the term "event" as a meteorological episode that caused death, injures or damaged private and/or public properties. 
The answer to these questions requires knowledge of particular complexity. We need indeed to train experts with a transversal knowledge. The experts should not limit their understanding to technical and scientific expertise, they must also have a profound awareness in the fields of criminal and civil proceedings. Following the parallelism that we often referred to, the model too should be the figure of coroners in medicine as they are not only physicians but also, and more importantly, lawyers.

Experts should make their conclusions based on principles of excellence (of the supported scientific theses), independence (as opposed to personal interests) and transparency (of the method and reasoning applied). For the European Commission: "Whereas scientific advice on matters relating to consumer health must, in the interests of consumers and industry, be based on the principles of excellence, independence and transparency" (Commission Decision 97/579/EC of 23 July 1997 setting up Scientific Committees in the field of consumer health and food safety).

The experts should support the judge with data and analysis that must be reliable and have a factual validation. These must be accepted by the general scientific community and controlled through processes of refutation and corroboration.

Furthermore, experts should explain the cause of the event on the basis of scientific universal laws and robust statistics able to state that the verification of an event is invariably accompanied by occurrence of another event.

With these elements experts should explain whether the action or the omission caused the event or, oppositely, if the event happened because of a multiplicity of contributing factors not ascribable to the eventual omission of the guardian of CP.

Finally, the Judge, after hearing the opinion of the expert, in the absence of a scientific law that explains the elements of an accident (cause, avoidance, predictability) and which bonds the accident to the action/omission scheme, should declare it devoid of a "covering law". Indeed, the prosecution, in these cases, has to be prevented and, in any case, made acquittal as there is no proof of criminal responsibility beyond reasonable doubt.

\section{Conclusions}

In this paper we discussed the importance that uncertainty, of NWP models and forecasts, has both in the real time decision making command chain and in trials intended against $\mathrm{CP}$ operators and guardians. The examined case study (Vibo Valentia) showed how meteorological weather prediction can be faulty and gravely underestimate an incoming event. The margin of error is both temporal (When will the event happen? For how long?) and spatial (Where will it strike?). The discrepancy emerged from ex post analysis (Molini et al., 2009) tells us that state of the art instruments can possibly induce the operator of $\mathrm{CP}$ to make wrong decisions. In addition to computational and modelling problems, the complex orography of the Mediterranean basin and of Europe at large impedes to asses and characterize hydrometeorological risk with the sole support of NWP models. Different means of forecasting these events are although available: radar and satellite data, for instance, could represent a robust support to real-time data analysis. However the delay in data transfer, as solemnly stated in the defensive memories of the trial of Vibo Valentia, is yet an ulterior problem that has to be faced in this field. CP organizations are still undergoing structural ameliorations in this sense, but, until a 24/7/365 total coverage is reached, the best instrument in our hands is still represented by NWP models and by the experience of whom, on a daily basis, issues meteorological bulletins and alert. These are the foremost link between CPs and the population at large.

It is in these terms that we must think or, rather, rethink CP organizations. Implementing the best strategy at a national level, with the best equipment and the most advanced technologies, will not compensate the eventual disjunction between the core structure and the administrative periphery. A solid chain has to link the prime minister to the "last citizen" in a fluid and highly responsive system. Establishing operative mechanisms for the so called "last mile" must thus represent the effort of the researches to come.

The smallest municipalities should not fear abandonment from the centre and, vice versa, cogent and erga omnes rules must be implemented transversally, throughout the entire system with particular attention to the periphery of the system which, sensu lato, represents, in the last instance, the citizens. It is towards them that the entire structure of $\mathrm{CP}$ systems should drive in the effort to mitigate the effects of natural catastrophes and enhancing the resilience of all the communities, from the largest to the smallest.

Envisaging the problem of the overcriminalization phenomenon and its social consequences, episodes similar to the Vibo Valentia flash flood are extremely rare to count, however they create the basis for a much more dangerous problem: the reduction of the alert threshold. As guardians in the $\mathrm{CP}$ are evidently trying to reduce the possibility to be convicted by augmenting de facto, at a preoccupant rate, the number of alerts issued, the perception of risk, by the population, is concomitantly lowering due to the cry wolf syndrome. More generalized alerts are being issued covering entire regions; it is unconceivable that the administrations in such extended areas will, on a regular basis, put into place all the actions needed to prevent death or property losses.

The steps taken so far imposed the supremacy of forecasting systems on a response centred vision. It is however utterly important that municipalities and the population will be involved Civil Protection operations with a renovated attention to differed time actions. The resilience of a community, in fact, can be greatly augmented if a correct land use planning with strict enforcing rules is applied. As just said is true particularly in those countries that share a 
complex morphology with Italy and that are experiencing the effects of years of lasseiz faire in the field of urban planning (i.e. the reiterated episodes of Scaletta Zanclea October 2007 and 2009 or the flooding of the Var region in France June 2010).

Finally, a different approach for the definition of guilt of $\mathrm{CP}$ operators must be elaborated. A tangible risk that judges and citizens could experience in such a field is the unaccountability of $\mathrm{CP}$ personnel as consequence of the already stated principle of "incerta pro nullis habentur". No jury will condemn, in a criminal law proceeding, whom correctly followed codified guidelines relying on uncertain instruments. This paradigm of criminal law will, de facto, mostly penalize plaintiffs whom will hardly see their rights recognized both in moral and economical terms. Excluding thus unaccountability of $\mathrm{CP}$ operators from a rooster of possible options, a more appropriate judicial process could be represented by the creation of an external controlling body which is to be invested with enquiring powers following the path of enquiring committees as seen, for instance, in air traffic control. This structural change in the definition of guilt in criminal law proceedings would represent an epochal turning point. The proposed ad hoc commission of experts would grant a substantial casuistry skimming preventing, on the first hand, the phenomenon of overcriminalization and, on the second hand, would allow judges to focus their efforts on the control of violation of specific and precise behaviour (known ex ante) and of the most salient cases of generic guilt.

Concluding, the solution here above proposed is an attempt of avoiding the stringent and vicious circle of precautionary approaches in the introduction of new technologies (NWP models) and for the consequent overcriminalization problem. Borrowing a few words from Aaron Wildavsky:

"Knowledge grows through critical appraisal of the failure of existing theory to explain or predict events. Learning by criticizing implies that existing theory is in error - not necessarily absolutely, but relative to better knowledge. (...) it is not the ability to avoid error entirely, but learning how to overcome it that is precious" (Wildavsky, 1988).

On these basis we can argue and conclude that there will not be any learning if the precautionary principle is to be paraphrased into harsh self defensive measures adopted "ad acta" by CP authorities in order to reduce the risk of being condemned. The stringent effects of overcriminalization and self defensive behaviour will cause a slower introduction of new technologies; technologies which have been the core of the recent innovation in CP and, clear of any doubt, did increase its efficiency.
Acknowledgements. The authors are grateful to the group of three judges who gave us their advice, the staff of the Italian Civil Protection Department who took part on the analysis and discussions and, finally, Guglieglmo DeLuigi, of the Regione Liguria Civil Protection, Raffaele Rocco and Sara Ratto, of the Regione Valle d'Aosta Civil Protection, who supported us with their precious experience and valuable judgment.

This research was partially supported and developed under the Agreement of 24 July 2009 between the Department of Civil Protection of the Presidency of the Council of Ministers of Italy and CIMA Foundation.

Edited by: M.-C. Llasat

Reviewed by: E. R. Bartlett Castellà and L. Garrote

\section{References}

Brezntiz, S.: Cry Wolf: The Psychology of False Alarms, Lawrence Erlbaum Associates, Hillsdale, NJ, USA, February 1984.

Commission Decision 97/579/EC of 23 July 1997 setting up Scientific Committees in the field of consumer health and food safety, 1997.

De Franchis, F.: Dizionario Giuridico (Legal Dictionary), Giuffrè editore, Milano, 1996 (in Italian).

Euratom, 2007/162/EC: Council Decision of 5 March 2007 establishing a Civil Protection Financial Instrument, 2007.

Gibson, J.: Doctrinal feedback and (un)reasonable care, Virginia Law Review, 94(7), 1641-1714, November 2008.

Husak, D. N.: Overcriminalization: the limits of the criminal law, Oxford University Press, New York, 2008.

Kessler, D. and McClellan, M.: Do Doctors Practice Defensive Medicine?, Q. J. Econ., 111(2), 353-390, May 1996.

Klingman, D., Localio, A. R., Sugarman, J., Wagner, J. L., Polishuk, P. T., Wolfe, L., and Corrigan, J. A.: Measuring Defensive Medicine Using Clinical Scenario Surveys, Journal of Health Politics, Policy and Law, 21(2), 185-217, 1996.

Lawson, F. H., Anton, A. E., and Neville Brown, L.: Amos and Walton's introduction to French law, Clarendon Press, Oxford, 1967.

Lynch, P.: The origins of computer weather prediction and climate modelling, J. Comput. Phys., 227, 3431-3444, 2008.

Molini, L., Parodi, A., and Siccardi, F.: Dealing with uncertainty: an analysis of the severe weather events over Italy in 2006, Nat. Hazards Earth Syst. Sci., 9, 1775-1786, doi:10.5194/nhess-91775-2009, 2009.

OECD: Review of the Italian National Civil Protection System, OECD Reviews of Risk Management Policies, OECD, 2010.

Olson, W.: Overdeterrence and the Problem of Comparative Risk, in: Proceedings of the Academy of Political Science, New Directions in Liability Law, 37(1), 42-53, 1988.

Stella, F.: Giustizia e modernità. La protezione dell'innocente e la tutela delle vittime (Justice and modernity. The protection of the innocent and the tutelage of the victims), Giuffrè, 2003 (in Italian).

Studdert, M. D., Mello, M., Sage, W., Desroches, C., Zapert, K., and Brennan, T.: Defensive Medicine Among High-Risk 
Specialist Physicians in a Volatile Malpractice Environment, J. Amer. Med. Assoc., 293(21), 2609-2617, 2005.

U.S. Census Bureau: Income, Poverty, and Health Insurance Coverage in the United States: 2007, August 2008.

UNISDR (United Nations International Strategy for Disaster Reduction): The Structure, Role and Mandate of Civil Protection in Disaster Risk Reduction for South Eastern Europe, Geneva, 2009a.

UNISDR (United Nations International Strategy for Disaster Reduction): 2009 UNISDR Terminology on Disaster Risk Reduction, Geneva, Switzerland, 2009b.

Wildavsky, A.: Searching for safety, Transaction Publishers, 1988.

\section{Court rulings}

Bolam v Friern Hospital Management Committee, 1 WLR 583, 1957.

Supreme Court of the United States: In re Winship (No. 778), No. 778 Argued: 20 January 1970, Decided: 31 March 1970.

Supreme Court of United States of America, 509 U.S. 579, 1993.

Tribunale di Vibo Valentia: Ufficio del Giudice per le Indagini Preliminari, Reg. Sent. 76/09, 6 September 2009 (in Italian). 